\title{
12
}

\section{RENEWABLE ELECTRIFICATION PATHWAYS AND SUSTAINABLE INDUSTRIALISATION}

\section{Lessons learned and their implications}

\author{
Rasmus Lema, Margrethe Holm Andersen, \\ Rebecca Hanlin, and Charles Nzila
}

\begin{abstract}
What economic opportunities are involved in the process of renewable electrification in developing economies? This is a central question running through this book. Achieving these opportunities requires appropriate policy. Therefore, in this last chapter, we examine the evidence collected throughout the book and discuss the policy implications. We are particularly focused on the co-benefits that are attained from renewable electrification efforts in developing economies. Specifically, how these can be used to build long term learning and capabilities that have broader relevance for the economy than simply through the provision of green electricity. We start by setting out the motivation, framing and key research themes addressed in this book. We then present the findings regarding when and how renewable electrification can enhance local sustainable development outcomes. Our key argument is that it matters how green economic activities are organised. We, therefore, bring out the evidence from the various chapter of the book concerning the three key themes of the book, (a) projects design, organisation, and linkages, (b) deployment model and choice of technology, and (c) policies and political actors at the national and international level. We conclude the chapter by bringing out the implications, providing key pointers for policy action.
\end{abstract}

\section{Introduction}

The green transformation comes with important opportunities for economic development, both in advanced and developing economies. This is a widely held argument in policy circles as well as in the popular press. In developing economies, it can set in motion processes of economic development and transformation 
referred to as 'sustainable' or 'green' industrialisation (UNIDO, 2016). Yet, it is widely acknowledged that the link between the green transformation and sustainable industrialisation is not automatic and that it comes with considerable constraints in developing economies. The underlying motivation for the research brought out in this book was to gain a better understanding of the circumstances that can help to turn the opportunities into reality in low and lower-middle-income countries.

The central theme running through the chapters in this book is that it matters how green economic activities are organised: they can be designed in ways that are more or less conducive to the long-term development of local industry. Our key starting assumption was that sustainable industrialisation achievements often depend critically on the local availability of capabilities to change (i.e., 'innovate') existing relationships along the chains that connect users and producers in the creation and deployment of green technologies.

To explore this, we have focused on a particular type of green technology, i.e., renewable energy, and a particular setting, i.e., the use of such technology in low and lower-middle-income countries to expand and transform existing electricity systems. We refer to this as renewable electrification. It has the dual purpose of creating increased access to electricity while greening the overall electric power regime.

We adopt a dynamic perspective, conceptualising the relationship between renewable electrification and related industry development over time. On the one hand, as mentioned above, the capabilities going into the renewable electrification process are critical to the realisation of green industrialisation outcomes. On the other hand, the successive steps in the renewable electrification process each provide a platform for learning, i.e., accumulation of capabilities. These can either enhance the sustainable industrialisation outcomes of subsequent steps in the renewable electrification process or undermine them, if learning is limited. It is this contingent process of building innovation capabilities for sustainable industrialisation which we have sought to unpack in this book.

The first chapter (Hanlin et al., 2022, this volume) sets the scene and defines our questions while the second chapter (Andersen and Lema, 2022; this volume) provides our conceptual framework. The remaining nine chapters examine different aspects of the process of building innovation capabilities for sustainable industrialisation. The purpose of this final chapter is to summarise the main insights of the book and bring out their implications.

The chapter is structured as follows: the next section reiterates the key research themes addressed in this book in order to situate the findings in wider debates about pathways to sustainable industrialisation. The following section forms the bulk of the chapter. It conveys the findings regarding the relative importance and dynamics of different aspects of renewable electrification for enhancing capability outcomes. It is structured around aspects related to the three key themes of the book, (a) projects design, organisation, and linkages, (b) deployment model and choice of technology, and (c) policies and political actors at the national and international level. The final section brings out the implications for policy. We summarise key findings 
arising from the research presented in this book, with the hope that the pointers for policy action can prove useful for more sustainable pathways that combine primary energy benefits and secondary localised economic co-benefits in the context of renewable electrification and the green transformation more broadly.

\section{Pathways to sustainable industrialisation}

The central theme in this book concerns pathways leading towards systems change in the way green infrastructure development is conceived in policy and designed, developed, and implemented in practice so local economic benefits are achieved. We pay particular attention to benefits with long-run potential for sustainable industrialisation gains. In this respect, we draw on the notion of transformative pathways characterised by directionality, distribution, and diversity (Leach, Scoones, and Stirling, 2007) in order to envisage pathways in the renewable electrification processes towards sustainable industrialisation.

\section{Sustainable industrialisation}

The overall objective is to assess whether and how renewable electrification can lead to inclusive structural change. Before addressing how the chapters in this book answer this question and generate new insights, it is useful to recapitulate what we mean by sustainable industrialisation and how different pathways of renewable electrification might contribute to it.

Our notion of sustainable industrialisation is three-dimensional and implies that structural change meets economic, environmental, and social goals simultaneously. It means that the process of industrialisation increases the greening, durability, and inclusiveness of economic activities (Figure 2.3, Andersen and Lema, 2022; this volume).

The contribution of renewable electrification to greening of economic activities is obvious: it changes the structure of energy systems by adding new green energy sources. It has the potential to become a force of 'creative destruction' by dismantling existing high-carbon models as new energy innovations are created and diffused (Lema, Iizuka, and Walz, 2015). For many years, scholars, politicians, and practitioners thought that such creative destruction should and would be spearheaded in high-income economies because greening was costly. Low- and middle-income countries would therefore adopt a 'cleaning-up later' industrialisation model as envisaged by the notion of an environmental Kuznet curve (Pegels and Altenburg, 2020). However, there is increasing recognition that a 'greening now' model can be viable because early greening can bring economic co-benefits that can make positive contributions to the industrialisation process itself. As discussed in Hanlin et al. (2022; this volume), however, such positive contributions from renewable electrification are far from automatic in many low- and 
middle-income countries. This is because the localisation of benefits depends on pre-existing capacities and capabilities and because the industrial development potential of the greening process through renewable electrification is largely absent in policy debates.

The durability of the economic activities involved depends on whether or not they lead to relevant forms of 'upgrading', defined here as an increase in the overall skill content of products and services and the creation of dynamic capabilities in organisations and production systems. Upgrading helps to ensure that skills, assets and systems do not become redundant beyond their immediate purpose, in the context of fast technological change and globalisation. In the absence of upgrading (or in the case of outright downgrading), local economies may experience premature deindustrialisation and immiserising or welfare worsening growth (Kaplinsky, Morris, and Readman, 2002). It is important to recognise that durability of activities does not necessarily mean that these activities are (only) concentrated around manufacturing activities. Rather, this aspect of the sustainability of industrialisation means that it involves positive structural change overall, involving a shift in production towards higher-knowledge intensity of products and services reflecting underlying assets based on higher knowledge and skilled labour (Ciarli et al., 2018).

Sustainable industrialisation is a form of structural change that also involves inclusiveness when it comes to increasing the participation of firms and workers in the economic activities and their involvement as active contributors to change. Given the other aspects inherent to sustainable industrialisation - greening and durability - such participation may often be challenging because it involves entirely new skills and processes. The international dimension is therefore of central importance: one crucial aspect is that more local firms and workers are involved as opposed to only or mainly foreign firms that have superior capabilities and capacities. Within countries, the transition to renewables is often intertwined with overall efforts of electrification, involving service delivery to rural communities that have tended to be marginalised from processes created by typical industrial development strategies. A key aspect of ensuring increased inclusiveness in sustainable industrialisation is thus inclusion of local firms and workers into the learning processes involved in low carbon development (Johnson and Dahl Andersen, 2012).

Sustainable industrialisation is structural change in which economic activities are green, durable, and inclusive at the same time. There can be significant tensions between these three aspects of sustainable industrialisation (i.e., 'tradeoffs'). However, it is important to recognise that such mutually opposed pressures can be mitigated and brought about by strategies and policies of the key stakeholders involved. It is precisely this transformation of tensions into synergies, that should take centre stage in policy discussions: making the most of current renewable electrification efforts by re-shaping their pathways towards sustainable industrialisation. 


\section{Transformative electrification pathways}

Pathways describe the particular directions in which new technologies - in this case green electrification technologies - are shaped during the process of their creation, adoption and use. The nature of such shaping has direct links to the realisation (or not) of the multidimensional sustainability outcomes discussed above. As discussed earlier, research focused on the direction, distribution, and diversity dimension of pathways provides a useful entry point to analysing renewable electrification (Stirling, 2009).

Direction implies that different innovation pathways towards electrification are considered and that trajectories, which support multidimensional sustainability are supported. In this book, the issue of directionality is addressed in particular through the focus on deployment models and choices of technology. There is a great need to redirect deployment pathways in directions that favour types of technology that are more appropriate and models that meet a larger array of sustainability outcomes. While directionality is often considered at the systems level (e.g., energy systems), it is also important to consider how individual parts of the system (e.g., projects) take shape. In the context of this book, this includes the direction of technological capabilities being used and built in projects, specifically, the degree to which there is learning which implies a movement from capabilities to use green energy technologies towards capabilities that help develop wider skills and competences related to design and manufacturing (Bell, 2009). This requires dispersed innovative capabilities that are deeply and pervasively embedded in local renewable energy systems.

The aspects of distribution imply a focus on how renewable electrification can eventually provide positive gains to local workers and firms. This requires an assessment of winners and losers of the renewable electrification process when it comes to the appropriation of the co-benefits involved. It is about 'just sustainabilities' (Agyeman, 2008; Scoones, 2016) in the domain of economic co-benefits and their distribution. In this respect, a key aspect addressed in the book is about the distribution of economic gains from green electrification in sub-Saharan Africa (SSA), between local and foreign actors. Hitherto these benefits have been heavily skewed in favour of the latter. This includes both the economic dividends from investments and the enterprise profits arising from infrastructure delivery. As will be discussed further below, several chapters in this book show how foreign firms typically occupy almost every step in the electrification value chains and in particular the most profitable and learning-intensive ones. Immediate jobs and local demand stimuli along backward linkages are important (to the extent they arise), but access to learning and capability-building is critical in the longer run. Many capabilities involved in renewable electrification are lateral in nature and can be used in other infrastructure settings.

The need for diversity of pathways is essentially about diversity in the accumulation of knowledge and experiences (Scot and Steinmuller, 2018) and an acknowledgement of the unequal distribution of capabilities and relations of power between 
actors in this process (Ockwell and Byrne, 2016). In the context of this book it relates strongly to the need to rebalance capabilities to generate 'greater intensity and diversity of localised innovation that complements the role of technological imports' (Bell, 2009, p. 12). Our book highlights the difficulties of having structured and systematised diversity with different technologies and modes of organisation, because powerful (typically foreign) actors often create lock-in to certain pathways. Diversity needs to be deliberately designed into projects to circumvent this. The notion of 'sustainability experiments' discussed in Andersen and Lema (this volume) could be a vehicle to change this. Deliberate efforts to meet the multidimensional sustainability criteria and placing more emphasis on locally designed projects is a way forward, for example, as in China where experiments ('demonstration programmes') were designed to crowd-in local players in successive rounds of direction-changing projects. This does not entail that imports are entirely substituted or that foreign advice from consultants are abandoned. There will certainly still be a need for openness in such locally grounded projects, but foreign inputs would have a supporting role rather than being in the driving seat. In the area of renewable electrification, this emphasises the need to create learning spaces to enhance the local participation in the innovation and economic processes and not always to focus only on modes of organisation that are designed largely by foreign companies.

\section{Lessons learned}

By putting capabilities centre stage in the exploration of the connection between renewable electrification and sustainable industrialisation we are standing on the shoulders of a long research stream. This established body of research has emphasised the centrality of organisational capabilities in the analysis of local innovation (Ely et al., 2013; Lema, Izuka, and Walz, 2015; Vidican, 2014), technology transfer and collaboration (Bell, 2012; Ockwell and Mallett, 2013), and innovation systems (Altenburg and Pegels, 2012; Johnson and Dahl Andersen, 2012; Ockwell and Byrne, 2015) in the context of low carbon development. This body of research has helped to extend conventional focus on the socio-economic benefits arising directly from access to green energy to those that arise indirectly as potential co-benefits of the renewable electrification process itself, in particular the potential 'learning benefits' (see Hanlin et al., 2022; this volume; Andersen and Lema, 2022; this volume). In the following we start each of the three subsections with the broad research-guiding 'propositions' which are informed by this literature and which have helped steer our empirical work. We then discuss the key findings we can draw out from the research as lessons learnt.

\section{Project design, organisation, and linkages}

We started our research with the idea that the way renewable energy projects are designed and organised, and the type and quality of linkages they include, 
matters significantly for capability development in low and lower-middleincome countries. Specifically, we assumed that learning-by-doing would be limited because the 'doing' would tend to be done by foreign firms and workers and because knowledge transfer would not occur as an automatic byproduct of project activities. In extension, we assumed that whether or not learning occurs depends on the degree to which it is specifically planned for in the design phase. These features of project design are, in turn, also the choice of the 'project model' such as whether it is organised as a relatively closed turnkey project coordinated by a single lead agent or a more open and loosely coordinated project involving several collaborators. Here the assumption was that a more open project would provide opportunities for building local capabilities. We explore these assumptions, summarising our evidence, in the following.

The various studies included in this book suggest that the renewable electrification projects observed typically revolve around foreign-dominated modes of project organisation. Bhamidipati et al. (this volume) examining three major projects found that in terms of the flows and nature of the projects: benefits are constrained by the dominant pattern of full-package provision of EPC contract. The authors show that local staff were involved in the construction phase of some projects (e.g., 70-90\% of total project employees in one case), but most highly skilled activities were mainly carried out by foreign nationals, in these cases Chinese nationals. In the operation and maintenance phase of the three projects, fewer local staff were employed but for longer time. In some cases, handing over to local staff was not fully achieved because locals were not always sufficiently trained to take over. There were some backward linkages, e.g., from provision of local services and manufacturing inputs from local firms, but these tended to be limited.

Hanlin and Okemwa (2022; this volume) provide case studies of four different renewable electrification projects with the aim to examine interactive learning and capability-building in critical projects. In all four cases studied, foreign Engineering, Procurement, and Construction (EPC) firms have played a central role either across the project or for key parts of it. The EPC firms have tended to structure tasks and linkages in these projects. However, these case studies provide grounds for cautious optimism. They showed that valuable capabilities, particularly project management and linkage (or networking) capabilities, were being built. Specifically, the authors showed that these case studies reveal increasing possibilities for local companies to gain an EPC role, especially in small solar PV projects, and that the way contracts are formulated relating to project management has a bearing on the likelihood of backward linkages and capabilities-building in projects of all sizes.

The study by Karjalainen and Byrne (this volume) goes deeper by providing a categorisation of solar photovoltaic (PV) companies in Kenya and Tanzania according to their levels of innovativeness, focusing specifically on firms operating in the domain of off-grid electrification. They show that foreign PV companies operating in Kenya and Tanzania have more innovative capabilities than the local ones. At the same time, however, local firms involved in innovative off-grid 
electrification activities have learned novel techniques through joint ventures and partnerships with foreign firms. Many local innovative firms have had active international linkages.

The insights unearthed by Nzila and Korir (2022; this volume) provide a systematic comparison across five different renewable energy technologies and five different steps in the value chain drawing on a comprehensive survey undertaken in Kenya. The study shows that capabilities for renewable electrification deployment in the country are relatively high on average but with noticeable bottlenecks. The findings also indicate that while management capabilities are generally rated high, there are a number of areas that require improvements, in particular with respect to the capabilities to identify, assess, negotiate, and finalise project financing terms as well as capabilities within maintenance. It was further revealed that the overall capability levels are highest in the solar PV domain. These findings serve to reinforce the premise that (for a developing economy) learning, capability development and benefits of renewable electrification are not obvious across the renewable energy ( $\mathrm{RE}$ ) value chain since to a large extent they might be constrained by the (mostly external) dominant actors. Hence there is need for interventions geared towards harnessing the full benefits of renewable electrification, including directing a new paradigm: from continued dependence on external actors in most steps of the RE value chain to the targeted development of local capabilities.

The main insight, when cutting across these studies, is that local actors, while involved in all projects observed, tend to be marginally involved in renewable electrification projects. Overall, there is only little local content provided and it tends to be concentrated in (a) the provision of auxiliary inputs into the construction phase such as provision of e.g., rackings for solar PV projects or cements for the foundations of wind turbine projects or (b) the provision of routine operation and maintenance tasks such as cleaning of facilities. The modes of project organisation observed - typically the EPC model involving a foreign main contractor have left negligible scope for more technology-intensive functions such as overall project design or provision of critical inputs such as core technologies. This has typically meant that linkages are concentrated in areas with limited learning opportunities, insofar as provision of marginal inputs provide marginal access to the critical capabilities to design and orchestrate similar project in the future. This is important because the capacity to take on the role of project organisers locally may enhance project design that includes overall local 'secondary benefits' in terms of jobs, more critical local content, and further learning. In short, the prevalence of the EPC model in current green electrification means that local firms experience learning mainly in routine tasks but make little progress in tasks that may provide further opportunities for backward and lateral linkage creation.

This finding is important to the sustainable industrialisation debate and takes centre stage in the insights provided by this book. Meanwhile, it is important both to bring out further the material that provides clear-cut support for it and also the exceptions and boundaries and to explain some of the key factors that help to explain this state of affairs. 


\section{Deployment model and choice of technology}

Project designs, including their internal organisation and external linkages, do not exist in a vacuum. They are dependent on overall renewable 'deployment models' that may vary significantly between countries, but they are dynamic, changing over time, and several paths may develop simultaneously (Lema et al., 2018). Key dimensions of such models are overall choice of renewable energy sources (the balance of hydro, solar, wind, etc.) versus sources, project size (e.g., many solar panels versus few or small versus large hydro) and technology sizes (e.g., small versus large wind turbines). They also include typical ownership structures and degree of international openness. In this book we have paid particular attention to centralised versus decentralised models and associated choices of technology where technology is understood in a broad sense. It is important to recognise that there are significant trade-offs in the realm of primary benefits - between e.g., on the one hand, economies of scale, speed of deployment, and so-called proven business models, and, on the other hand, geographical reach (in particular to rural communities and integration with new business models involving mobile money). But our focus has been on the secondary benefits in terms of direct economic activities (jobs and local content) and associated capability-building. Below we bring together key insights arising from the chapters in this book.

Several chapters in the book emphasise that the overall choice of core technology is crucial for learning opportunities. The majority of chapters are focused on wind and solar technologies, but some chapters also include analyses of geothermal energy and biomass powers (Nzila and Korir, 2022; this volume; Ogeya et al., 2022; this volume). The chapter by Nzila and Korir (2022; this volume) is key in this respect because it includes a systemic comparison across technology types. They found that local capabilities were acquired in PV and small hydro to a greater extent than in biogas, geothermal, and wind energy. In the latter group, capability development constraints were particularly pronounced in the areas of servicing and maintenance capability. Other chapters reinforce this finding, in particular with respect to solar PV. This technology, as compared to other renewables, has a lower share of upfront capital cost in overall project costs, meaning that the share of cost activities related to installation (and associated peripheral equipment), operation, and maintenance is higher. These activities provide opportunities for local involvement and learning.

Hansen et al. (2022; this volume) make the argument that although the nature of core technology has implications for secondary benefits, it is rather the 'size', which is critical. It is more in this sense that the choice of technology is crucial and has huge implications, for instance for how projects are organised and hence also for options for learning and capability-building. The same theme is picked up by Wandera (this volume) who argues that small wind has particular benefits compared to large wind as this technology exhibits features of appropriate technology such as simplicity, low capital 
cost, and ease of maintenance. Wandera does lend cognisance to the fact that small wind is only viable in areas with high surface wind speeds, and further argues that solar-wind-battery-hybrids have significant but untapped potential in Kenya and in other SSA countries (Johannsen, Østergaard, and Hanlin, 2020; Wandera, 2020). However, Hansen et al. (2022; this volume) emphasise, in particular, that large differences in learning and local economic development opportunities are related to whether projects are deployed on or off the national grid. They support the small is beautiful argument in the sense that there are more local learning possibilities in off-grid renewable projects which are small in size compared to projects feeding the grid.

These findings are echoed by Hanlin and Okemwa (2022; this volume) who provide in-depth insights into the process of learning across projects of different sizes. As mentioned above, they emphasise the observation that capabilitybuilding is constrained in EPC projects but there is evidence of local firms doing more engineering, procurement, and construction in small-scale projects. There is limited evidence of 'strategic' project management roles, even in small-scale projects as well as in the provision of technology. Local tasks are mainly 'routine' roles in construction, operations, and maintenance whereas foreign firms tend to cater for project design and coordination of construction.

Karjalainen and Byrne (2022; this volume) suggest that 'foundational capabilities' are built that could support sustainable industrialisation in a small-scale decentralised setting. Focusing on the off-grid solar PV sector in Kenya and Tanzania, they trace learning over 30 years and show that firms emerging in the 2010s and operating in Kenya and Tanzania have become globally leading. While most highly innovative companies are of foreign origin, this creates opportunities for local firms to strengthen their learning and potentially enter an 'early latecomer' phase where they could build increasingly complex capabilities, including for manufacturing. Models for forming use of technology appear more important than choice of technology/core technology. Innovations are focused largely on business models, but they also show that cash-sales of solar PV remain important and may be more valuable for local firms compared to the (centralised) PAYG model.

Another aspect of 'pathway models' regards their international openness. It is well-known that electrification efforts in SSA are quite heavily influenced by international actors across the value chain, from finance over equipment provision to project execution (Lema et al., 2018). The precise degree of external dependence is difficult to specify, but as earlier mentioned, foreign lead firms tend to take on coordinating roles. Interestingly, Gregersen and Gregersen (2022; this volume) explore 'learning spaces' in foreign-dominated projects in large scale wind, one European and one Chinese project. Focusing on how interactions between different stakeholders in wind power 'megaprojects' can lead to the accumulation of technological and managerial capabilities, they show that both formalised and tacit knowledge interaction can occur, even in the megaproject setting, but it has limits. 
The chapter by Bhamidipati et al. (2022; this volume) also examines large projects, focusing on three Chinese projects, with the aim to examine the realisation of co-benefits (i.e., secondary benefits). They show that the choice of (core) technology is decided by key decision-makers in each of the three projects as a part of financing deals. The element of finance is significant because it shifts the relative bargaining power strongly in favour of the investor-contractor consortium, making co-benefits largely dependent on the actors engaged with making key decisions with regard to the project. Core components and equipment are almost exclusively imported from China or alternatively sourced from specialised suppliers in advanced economies. Apart from the primary benefits of electricity provision, local socio-economic benefits arising from the electrification process itself (secondary benefits) ranges between 'very few' and 'extremely few'.

Collectively, the chapters in this book show that patterns of learning capabilities and outcomes differ markedly between types of technology and between deployment models. Most of the evidence unearthed supports the argument that wider socio-economic benefits can be achieved more easily in small-scale decentralised models, but even here these benefits depend on key contingencies. We address these in the next section.

\section{Policies and political actors at the national and global level}

The following section brings out the key implications for policy arising from the research presented in this book. In this present section our focus is different: we aim to bring out insights about how policies and political actors influence capability-building directly and through influencing deployment models and modes of project organisation. Some of the chapters in the book address policy issues as their key focus while others deal with the policies as a part of their overall analysis.

The chapter by Kingiri (this volume) is explicitly focused on the role of policy and goes some way in explaining the prevalence of observed deployment models and modes of project organisation. It presents a historical analysis of Kenya's policy process in renewable electrification from 1999 to 2019 with a particular emphasis on the efforts to promote industrialisation in the energy sector. The chapter draws on a stakeholder survey of key policy gaps that require policy support in developing requisite capabilities for support to sustainable industrialisation. Although local content issues, as a result of pressure from various stakeholders, are becoming more pronounced in the discourse and agenda, it is still not fully implemented and reinforced. A key issue highlighted in the chapter is that this is difficult due to both domestic factors, such as limited manufacturing capabilities, and due to external factors, such as high levels of competition from other countries (China included) as far as production of solar PV and other equipment is concerned. In an illustration of this, the chapter by Karjalainen and Byrne (2022; this volume) shows how attempts to develop the local manufacture 
of battery charge regulators for solar home systems failed because of better quality and cheaper products imported from China.

In other words, while local content policies exist on paper, they are difficult to implement in reality, because of pressure/conditions from providers of finance combined with a 'mismatched' or uncompetitive local supply base. The latter is also related to the education system where specific training efforts in some Kenyan universities and Technical Vocational Education and Training Institutions (TVETs) do not fully meet the production and innovation needs associated with the renewable electrification process. As a result, one chapter in the book (Ogeya et al., 2022; this volume) highlights the existence in Kenya of a 'locked-in' system where change is difficult to achieve due to existing institutions and political structures.

Bhamidipati et al. (this volume) address similar issues and seek to examine 'local institutional and economic conditions' as key determinants of learning, linkages, and local content (economic co-benefits) arising from three green energy projects in Kenya, Ethiopia, and Ghana respectively. They find that in all three cases, there were local content policies in place but these policies were largely circumvented in project contracts. They highlight both policy effort and inequalities in bargaining power between external consortia (bringing together finance, equipment, and services) and local stakeholders, in particular governments but also other firms and organisations involved in the project.

This aspect is also clearly illuminated by Gregersen and Gregersen (2022; this volume). In the Ethiopian case, the government has gone beyond production-system thinking and involved knowledge and innovation-system building elements to ensure more local learning in and around projects. While still with several shortcomings, the Ethiopian Government has taken an active role in design of projects to ensure maximum local learning, by ensuring that professional users are more involved in the project execution. This, according to the authors, explains that while there was some local learning in both the Kenyan and the Ethiopian cases in the field of O\&M and how to add more renewable energy to the national grid, the Ethiopian Adama case involved slightly more learning about how to design a (large-scale) renewable energy project.

Another important aspect concerns the policy support for traction in the different dimensions of the deployment model. Hansen et al. (2022; this volume) show that a disaggregated level of analysis is important for understanding (and ultimately designing) policies in the renewable electrification field. Hence the overall focus on policies for 'renewables' needs to be decomposed in ways that are sensitive to different types of renewable technologies and, in particular, the different versions of these renewables that are supported, e.g., standalone versus grid-connected solar. As argued above, these have very different potential outcomes in terms of benefits and their distribution. Governments support different renewables and deployment models that can imply benefits at different scales and in different contexts (e.g., urban/rural). Overall, the political economy dynamics 
tend to favour 'proven' models with powerful lead firms and strong economies of scale in large projects.

In continuation, Wandera (2022; this volume) argues that despite - or perhaps because of - the huge attention to large wind in Kenya, there has been limited support and a formation of a very weak (if not absent) system of small wind deployment in Kenya. When it comes to rural and decentralised deployment, rooftop solar PV has received more attention than hybrid mini-grids that are more technically demanding and have higher upfront investment costs. However, this is slowly changing and more conducive policies, e.g., for more wind used in hybrid off-grid systems, may alter the role of small wind turbines (SWT). Yet, a recent donor-funded experimental project to increase small wind (Kenya's Miniwind project) has been discontinued due to the complexities involved in cross-function collaboration and development of viable business models.

Karjalainen and Byrne (2022; this volume) tell the other side of this story, showing how multiple donor projects in the late 1990s and early 2000s supported the deployment of solar PV, through technical skills training and awareness activities. These were highly successful in rolling out solar home systems (SHS), but economic arrangements have been left to the market forces and have not helped individual companies to catch up and arrange for the localisation of products and services.

In sum, this book shows that socio-economic outcomes of renewable electrification - their contribution to sustainable industrialisation - are influenced by disparate policy fields, chiefly energy policy and industrial policy, that are rarely brought together to make the most of ongoing economic activities. In particular, deliberate policies towards capability development are strikingly absent. Although important opportunities have been identified in and around the economic activities involved in the electrification process, they are rarely formulated let alone implemented. In the following section we set out an interpretation of our findings against key normative objectives as specified in Hanlin et al. (2022; this volume), before proposing key suggestions for policy.

\section{Conclusions and pointers for policy action}

We started this chapter by observing that the green transformation comes with opportunities and constraints for economic development, but that these differ markedly between countries. In many high-income economies, the objective to maintain and expand high levels of economic development and welfare with this transformation is embedded in the notion of 'green growth' (Bowen and Fankhauser, 2011). Emerging economies such as China and India seek to exploit changes in global markets and technologies to increase the pace of latecomer development (Pegels and Altenburg, 2020). But while such strategies have been effectively crafted in advanced and in emerging economies, what might the windows of opportunity look like in low and lower-middle-income countries? And what will it take to realise such options? 
In this book we have sought to address these questions by focusing on renewable electrification as a case in point to examine its contribution to sustainable industrialisation. If renewable electrification in lower-middle-income countries does not contribute effectively to sustainable industrialisation, there is no reason to assume that other elements of the green transformation (energy efficiency, mobility, etc.) would.

We have drawn on a conceptual framework focusing on learning, capabilities, and outcomes. As set out in Chapter 2 (Andersen and Lema, 2022; this volume), we have put forward the argument that sustainable industrialisation outcomes depend on the local learning opportunities involved in the underlying economic activities. Hence, a more specific question has driven our work: what economic opportunities are involved in the process of renewable electrification in developing economies and how can policy help to ensure that such opportunities are realised in a way that makes maximum contributions to structural change? So far there are surprisingly few insights regarding this question, for two main reasons.

The first reason is that some analysts and global policy makers still consider these questions superfluous because the primary (green energy) benefits should, in their view, take precedence. Hence, the argument goes, renewable electrification - even without noticeable local economic benefits - should be pursued due to its climate change and energy security advantages. They reason that the green transformation is cheaper overall when 'delivered' by actors with pre-existing technologies and capabilities, as opposed to when it is delivered by those firms who need to pay the additional costs of moving along a technological learning curve.

In this book, we argue that this viewpoint is critically flawed. First, delivery of green energy by external firms and agents may create path-dependency and longrun lock-in to external solutions. Second, overly depending on external actors in the provision of green energy entails big risks in terms of 'technological fit' of new facilities and in terms of operation, maintenance, and sustainable use of the renewable energy systems already installed. Third, the long-term viability of the green transformation depends on popular legitimacy and support, which requires localisation of economic benefits. It needs to be supported by realistic prospects of green economic development in low- and middle-income countries and not just by 'green growth' in advanced economies. There are strong links between the first and the third of these arguments to the recognition of the overall importance of equity in climate change policy (Klinsky et al., 2017), in particular when it comes to climate change mitigation as a cornerstone of the green transformation.

The second reason is that although some of these counterarguments have been taken on board and the discourse has (to some extent) expanded from primary benefits to economic co-benefits, this discourse has been based on assumptions that do not hold. A key conclusion arising from our work is thus that communities and policymakers need to beware of overly optimistic expectations about the secondary (economic) benefits that renewable electrification projects may generate in low- and middle-income countries. These benefits tend to be limited and 
they are not automatic by-products of the expansion and modification of energy systems with renewables. More generally, a major argument in our book is that the specificities of green development in low- and middle-income countries are insufficiently understood and are also insufficiently incorporated into the global and local policy discussions.

So, whereas the strategies of green growth may work in advanced economies, the evidence unearthed in this book suggests that it has much less potential in the low- and middle-income countries, in particular if conducted as business-as-usual. In order to make it 'work', a number of major changes are required in policy. In the remainder of this chapter, we bring together and discuss new kinds of policy action which could be explored in different contexts. We outline key policy deliberations across national and global levels of policymaking and a summary of these is provided in Box 12.1. We call them key 'pointers' for policy action because they need to be carefully interpreted, assessed, and shaped depending on circumstances, local industrial context, specific features of the technologies in question etc.

However, these suggestions are all underpinned by one central idea running through this book, namely the need to make economic co-benefits a requirement of green transformations in developing economies. This necessitates persistent expansion of the policy focus from primary benefits to economic co-benefits. As discussed in this book, it also entails that production and innovation capability development is put centre stage in all aspects of green transformation policy, such as those dealing with local firms, projects, and organisations relevant for renewable electrification.

\section{BOX 12.1 SUMMARY OF KEY POINTERS FOR POLICY ACTION}

1. Combine plans of energy system greening with industrial development and technological development strategies. This requires that policy domains that typically develop separately - i.e., the energy-environmental and industrial development domains - are aligned, co-designed, and developed in conjunction.

2. Ensure frameworks for project selection, such as auction systems, and increase accountability and selection criteria across a broader set of industrial development goals as opposed to just energy production.

3. Make local co-benefits a key criterion for selection of projects. Devise and use impact assessments for skilled jobs, local content, and capability development prior to any project decision.

4. Re-balance the emphasis on capability development in energy projects away from the conventional focus on renewable energy project service delivery (operation and maintenance) to pay more attention to renewable energy project infrastructure delivery (particularly project design and execution). 
5. Create in-depth maps of renewable energy supply chains and focus on capacity and capability-building in 'zones of proximate development' (capabilities that are within reach, but not yet acquired locally) in both the manufacturing and deployment chains of sustainable energy projects.

6. Create learning spaces such as experimental projects (sustainability experiments), that try out not only different types of technologies, but also different new types of project management, localised supply, and community involvement. Document and use the experience in revising project selection and design criteria.

7. Create national agencies that can function as vessels of domain expertise, enable systematic learning, and facilitate knowledge transfer between different successive and otherwise unconnected projects.

8. Create a network of national 'centres of excellence' in universities and vocational training institutions and make sure to insert national education institutions into renewable energy projects as partners/learning consultants.

9. Help national consortia to bring together finance from impact investors with local and global companies for projects that meet the multidimensional sustainability criteria and related learning objectives.

10. Build multi-stakeholder global coalitions to define and implement mission-oriented innovation programmes with the aim to use greening transformation initiatives to foster structural change. Make finance from progressive institutional investors a cornerstone.

At the national level, plans of energy system greening must be persistently combined with industrial development and technological upgrading strategies. This requires that policies that typically develop in separate policy domains need to be co-created across the energy-environmental and industrial spheres. For example demand-driven initiatives to facilitate energy system greening, such as feed-in tariffs or auctions, need to develop in alignment with active industrial policy and appropriate measures to ensure the appropriate localisation of economic activities (Landini, Lema, and Malerba, 2021). As shown in several chapters in this book, the thorough analysis of past provision of green energy facilities can enable the identification of value chain activities that can feasibly be undertaken by local firms, thereby substituting currently imported capacities and capabilities. Such tailored strategies should be developed and adjusted dynamically to identify zones of proximate development in the upgrading process (developing capabilities that are within reach) and involve the targeted development of support systems, in particular the provision of relevant knowledge infrastructures for the cultivation of relevant design, engineering, and management capabilities. 
In other words, the co-designing of policies needs to be closely coordinated with long-term national energy plans and nationally appropriate mitigation actions (NAMAs). This should also ensure that national development plans determine green transformation activities, not the other way around. Systemic frameworks, such as energy auctions, that assess and approve project selection should be pro-actively designed and implemented to raise investment and ensure favourable tariffs. Importantly, they should also ensure that projects are not developed on an ad-hoc basis promoted by specific consortia of finance and technology supply (see Bhamidipati et al., this volume). Ad-hoc project approval weakens the bargaining power of governments and typically comes along with informal 'foreign content requirements' tied to external sources of finance. Frameworks for project selection and approval must be focused on a broader range of goals to address the issues of directionality, diversity, and distribution discussed above. In this respect, the capacity of local authorities to design and manage according to 'guiding visions' is key (Lema et al., 2018).

When it comes to crafting such guiding visions, it is important to keep in mind that renewable electrification essentially is a process of successive provisions of discrete green infrastructure projects. As discussed above, localisation and learning does not arise automatically in these renewable energy projects. Therefore, deliberate and upfront planning of local content provision and capability development is needed for every single project and throughout the various stages of decision-making. The required measures do not work when they are supplementary add-ons provided after other technical and financial specifications are defined. Hence, these concerns need to move centre stage at the point of initial impact assessment and feasibility reporting to be able to select the projects with the largest scope for creating economic benefits, and they need to be included in the process of project design in order to make sure that this potential is realised. The stage of project design is where the key supply chain decisions are made, and hence this is where appropriate local rooting can be ensured.

Related to this, local content can only be built into projects if there are capabilities on the ground. A key problem of policy-design for renewable electrification is the temporal and specialised nature of projects, in particular for large-scale projects and pathways. Major projects may only be constructed a few times every decade. Incidentally, this is an additional argument for intensifying the exploration of smallscale, decentralised pathways. These are more frequent and have lower barriers to entry for local firms. Mid-size mini-grids may well be constructed by developers from low- and middle-income countries. Innovative business models developed in East Africa, as described in this book (see e.g., Karjalainen and Byrne (2022; this volume) may provide a platform for the attainment of market shares in this segment.

Whether they are small or large-scale projects, there is no guarantee of repeated involvement of particular national firms in a context of competitive bidding. Therefore, it is particularly important to create government agencies that can function as vessels of domain expertise, enable systematic learning, and 
facilitate knowledge transfer between different successive and otherwise discrete and unconnected projects. It is important to recognise, moreover, that several lateral capabilities are involved in the provision of green energy, i.e., capabilities that are involved in other types of infrastructure provision activities, be it ports, bridges, or railway lines. Government agencies can thus be supported by centres-of-excellence in infrastructure project management, located in key national universities, research institutes, and technical training and vocational institutes, which need to be invited on board as project partners involved in assessment and design as well as capability development and knowledge acquisition and collaboration.

Such requisite organisational entities, in particular the key government agencies, need to facilitate a diversity of capabilities, ranging across different domains from project management to more specific technological capabilities. They also need to accumulate experiences relevant to different sizes of projects, e.g., both large and small scale. Crucially, they also need to function as climate-relevant innovation system builders (Ockwell and Byrne, 2015) taking on the central role of forging relationship between firms and between firms and supporting institutions. In this way, virtuous circles of co-development of specific renewable energy projects with enhanced long-term capabilities in sustainable industrialisation may be generated.

Focused efforts to create learning spaces such as experimental projects or 'sustainability experiments' are important in this respect (Berkhout et al., 2010). One area where our work has highlighted the need for more experimentation is in project design, project management, and infrastructure delivery (execution) more generally. There is a need to re-balance the emphasis on capability development in energy projects away from the conventional focus on renewable energy project service delivery (operation and maintenance) to pay more attention to renewable energy project infrastructure delivery (particularly project design and execution). Therefore, these sustainability experiments should try out not only different types of technologies, but also different new types of project management, localised supply, and community involvement. These efforts must be documented and reviewed so the experiences can be taken on board and utilised in future project design. Crucially, the learning should be considered by those involved in project selection too - i.e., that more learning is built into the policy process; to close the loop in the policy process from implementation back to planning and designs.

These points have profound implications for the design of policies and support schemes of global institutions and global bilateral programmes. There is a need to coordinate and align objectives across global policy domains as well. Hence, international decision-makers need to work together to create policy packages, cutting across climate policy, and trade and development policy, for locally beneficial renewable electrification pathways. The raison d'être of such policy packages should be to create the economic co-benefits necessary to incentivise the exploration of new pathways of sustainable industrial development locally. It is necessary to increase the scope of national decision-making and introduce 
deliberate local learning in all elements of renewable energy interventions and related climate actions. It is not sufficient to devise such schemes based on the notion that cost-effective climate change mitigation trumps the localisation of economic benefits, such as technological and organisational learning as well as backward linkages to locally rooted supply chains. Increased awareness of what it takes to design projects in a manner that take into account needs for local learning and involvement is an obvious area for deepened government-to-government collaboration and mutual capacity building.

The principles above require a global system, which works actively to substitute imported capabilities with local ones, where in practical terms such substitution is achieved by assisting to build capabilities in low and lower-middle-income countries. In turn, it depends on a contentious but necessary acknowledgement that the economic interests of powerful global stakeholders need to be curbed and brought into alignment with national priorities for example in sub-Saharan Africa, thereby increasing fairness and popular legitimacy to support global support for the green transformation. This requires a disassociation between soft loans or aid for green energy and infrastructure and contracting decisions favouring global vested interests. Global agreements and standards are needed to ensure such separation. Moreover, every financing decision must include economic cobenefits from the initial point of project negotiations, not in exceptional cases but as a requirement instituted in global policy frameworks. They should be included in public Official Development Assistance (ODA) guidelines and in private environmental, social, and corporate governance (ESG) indicators.

In sum, considerable efforts are required in projects and at national and global levels to ensure that the possible economic co-benefits of renewable energy projects for sustainable industrialisation are realised. These need to be at the heart of current debates about 'leapfrogging' to avoid the fossil-fuel based energy scenarios of high-income countries. In other words, there is a need for entirely new visions for development pathways around renewable electrification which brings together the objectives of energy system greening, access to energy, and economic development. It requires a recasting of sustainability transition narratives, broadening the scope to incorporate a wider range of multidimensional sustainability criteria - to include economic and social dimensions - explicitly and centrally into multilateral and national policy frameworks.

\section{References}

Agyeman, J. (2008) 'Toward a 'Just' Sustainability?', Continuum, 22(6), pp.751-56.

Altenburg, T. and Pegels, A. (2012) 'Sustainability-Oriented Innovation Systems Managing the Green Transformation', Innovation and Development, 2(1), pp. 5-22.

Andersen, M.H. and Lema, R. (2022) 'Towards a Conceptual Framework: Renewable Electrification and Sustainable Industrialisation', in Building Innovation Capabilities for Sustainable Industrialisation: Renewable Electrification in Developing Economies. New York: Routledge. https://doi.org/10.4324/9781003054665-2 
Bell, M. (2009) Innovation Capabilities and Directions of Development. Vol. 33. Brighton: STEPS Centre.

Bell, M. (2012) Low-Carbon Technology Transfer. London: Routledge.

Bhamidipati, P.L et al. (2022) 'Chinese Green Energy Projects in Sub-Saharan Africa: Are There Co-Benefits?', in Building Innovation Capabilities for Sustainable Industrialisation: Renewable Electrification in Developing Economies. New York: Routledge. https://doi .org/10.4324/9781003054665-10

Bowen, A. and Fankhauser, S. (2011) 'The Green Growth Narrative: Paradigm Shift or Just Spin?', Global Environmental Change, 21(4), pp. 1157-59.

Ciarli, T., Savona, M., Thorpe, J. and Ayele, S. (2018) Innovation for Inclusive Structural Change. A Framework and Research Agenda. Brighton: Science Policy Research Unit.

Ely, A,, Smith, A., Stirling, A., Leach, A. and Scoones, I. (2013) 'Innovation Politics PostRio+20: Hybrid Pathways to Sustainability', Environment and Planning C: Government and Policy, 31(6), pp. 1063-81.

Gregersen, C. and Gregersen, B. (2022) 'Interactive Learning Spaces: Insights from Two Wind Power Megaprojects', in Building Innovation Capabilities for Sustainable Industrialisation: Renewable Electrification in Developing Economies. New York: Routledge. https://doi.org/10.4324/9781003054665-8

Hanlin, R. and Okemwa, J. (2022) 'Interactive Learning and Capability-Building in Critical Projects', in Building Innovation Capabilities for Sustainable Industrialisation: Renewable Electrification in Developing Economies. New York: Routledge. https://doi .org/10.4324/9781003054665

Hanlin, R., Andersen, M.H., Lema, R. and Nzila, C. (2022) 'Renewable Electrification and Sustainable Industrialisation', in Building Innovation Capabilities for Sustainable Industrialisation: Renewable Electrification in Developing Economies. New York: Routledge. https://doi.org/10.4324/9781003054665-1

Hansen, U.E. et al. (2022) 'Centralised and Decentralised Deployment Models: Is Small Beautiful?', in Building Innovation Capabilities for Sustainable Industrialisation: Renewable Electrification in Developing Economies. New York: Routledge. https://doi.org/10.4324 19781003054665-4

Johannsen, R.M., Østergaard, P.A. and Hanlin, R. (2020) 'Hybrid Photovoltaic and Wind Mini-Grids in Kenya: Techno-Economic Assessment and Barriers to Diffusion', Energy for Sustainable Development, 54, pp. 111-126.

Johnson, B. and Dahl Andersen, A. (2012) Learning, Innovation and Inclusive Development: New Perspectives on Economic Development Strategy and Development Aid. Aalborg, Denmark: Aalborg University Press.

Kaplinsky, R., Morris, M. and Readman, J. (2002) 'The Globalization of Product Markets and Immiserizing Growth: Lessons from the South African Furniture Industry', World Development, 30(7), pp. 1159-77.

Karjalainen, J. and Byrne, R. (2022) 'Moving Forward? Building Foundational Capabilities in Kenyan and Tanzanian Off-Grid Solar PV Firms', in Building Innovation Capabilities for Sustainable Industrialisation: Renewable Electrification in Developing Economies. New York: Routledge. https://doi.org/10.4324/9781003054665-9

Kingiri, A. and Okemwa, J. (2022) 'Local Content and Capabilities: Policy Processes and Stakeholders in Kenya', in Building Innovation Capabilities for Sustainable Industrialisation: Renewable Electrification in Developing Economies. New York: Routledge. https://doi .org/10.4324/9781003054665-11

Klinsky, S., Roberts, T., Huq, S., Okereke, C., Newell, P., Dauvergne, P., O’Brien, K., Schroeder, H., Tschakert, P., Clapp, J., Keck, M., Biermann, F., Liverman, D., 
Gupta, J., Rahman, A., Messner, D., Pellow, D. and Bauer, S. (2017) 'Why Equity Is Fundamental in Climate Change Policy Research', Global Environmental Change, 44, pp. 170-73.

Landini, F., Lema, R. and Malerba, F. (2021) 'Demand-Led Catch-up: A HistoryFriendly Model of Latecomer Development in the Global Green Economy', Industrial and Corporate Change, 29(5), pp. 1297-1318.

Leach, M., Scoones, I. and Stirling, A. (2007) Pathways to Sustainability: An Overview of the STEPS Centre Approach. Brighton: STEPS Centre.

Lema, R., Hanlin, R., Hansen, U.E. and Nzila, C. (2018) 'Renewable Electrification and Local Capability Formation: Linkages and Interactive Learning', Energy Policy, 117(August 2017), pp. 326-39.

Lema, R., Iizuka, M. and Walz, R. (2015) 'Introduction to Low-Carbon Innovation and Development: Insights and Future Challenges for Research', Innovation and Development, 5(2), pp. 173-87.

Lema, R. et al. (2022) 'Renewable Electrification Pathways and Sustainable Industrialization: Lessons Learned and Their Implications', in Building Innovation Capabilities for Sustainable Industrialisation: Renewable Electrification in Developing Economies. New York: Routledge. https://doi.org/10.4324/9781003054665-12

Nzila, C. and Korir, M. (2022) 'Are the Capabilities for Renewable Electrification in Place? A Kenyan Firm-Level Survey', in Building Innovation Capabilities for Sustainable Industrialisation: Renewable Electrification in Developing Economies. New York: Routledge. https://doi.org/10.4324/9781003054665-6

Ockwell, D. and Byrne, R. (2015) 'Improving Technology Transfer through National Systems of Innovation: Climate Relevant Innovation-System Builders (CRIBs)', Climate Policy, 16(7), pp. 836-854.

Ockwell, D. and Mallett, A. (2013) 'Low Carbon Innovation and Technology Transfer' in Urban, F and Nordensvärd, J. (eds.) Low Carbon Development: Key Issues, pp. 10928. Abingdon: Earthscan, Routledge.

Ogeya, M.C., Osano, P., Kingiri, A. and Okemwa, J. (2022) 'Challenges and Opportunities for the Expansion of Renewable Electrification in Kenya', in Building Innovation Capabilities for Sustainable Industrialisation: Renewable Electrification in Developing Economies. New York: Routledge. https://doi.org/10.4324/9781003054665-5

Pegels, A. and Altenburg, T. (2020) 'Latecomer Development in a 'Greening' World: Introduction to the Special Issue', World Development, 135, pp. 1-11.

Scoones, I. (2016) 'The Politics of Sustainability and Development', Annual Review of Environment and Resources, 41, pp. 293-319.

Stirling, A. (2009) Direction, Distribution and Diversity! Pluralising Progress in Innovation, Sustainability and Development. Brighton: STEPS Centre.

UNIDO (2016) 'Industrial Development Report 2016: The Role of Technology and Innovation in Inclusive and Sustainable Industrial Development', Vienna.

Vidican, G. (2014) 'Challenges and Opportunities for Capturing Local Benefits', Ökologisches Wirtschaften-Fachzeitschrift, 29(4), p. 19.

Wandera, F.H. (2020) 'The Innovation System for Diffusion of Small Wind in Kenya: Strong, Weak or Absent? A Technological Innovation System Analysis', African Journal of Science, Technology, Innovation and Development, (in press) pp. 1-13.

Wandera, F. (2022) 'Understanding the Diffusion of Small Wind Turbines in Kenya. A Technological Innovation Systems Approach', in Building Innovation Capabilities for Sustainable Industrialisation: Renewable Electrification in Developing Economies. New York: Routledge. https://doi.org/10.4324/9781003054665-5 
$\Longrightarrow$ Taylor \& Francis Taylor \& Francis Group

http://taylorandfrancis.com 